\title{
Teacher-Child Interaction in a Goal-Oriented Preschool Context: A Micro-Analytical Study
}

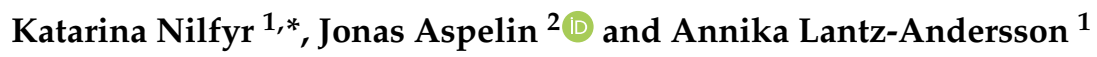 \\ 1 Department of Education, Communication and Learning, University of Gothenburg, \\ 40530 Gothenburg, Sweden; Annika.lantz-andersson@ped.gu.se \\ 2 Faculty of Teacher Education, Kristianstad University, 29188 Kristianstad, Sweden; Jonas.aspelin@hkr.se \\ * Correspondence: Katarina.nilfyr@hkr.se
}

check for updates

Citation: Nilfyr, K.; Aspelin, J.; Lantz-Andersson, A. Teacher-Child Interaction in a Goal-Oriented Preschool Context: A Micro-Analytical Study. Educ. Sci. 2021, 11, 692. https://doi.org/ 10.3390/educsci11110692

Academic Editor: Eleni Andreou

Received: 14 September 2021

Accepted: 27 October 2021

Published: 30 October 2021

Publisher's Note: MDPI stays neutral with regard to jurisdictional claims in published maps and institutional affiliations.

Copyright: (C) 2021 by the authors. Licensee MDPI, Basel, Switzerland. This article is an open access article distributed under the terms and conditions of the Creative Commons Attribution (CC BY) license (https:// creativecommons.org/licenses/by/ $4.0 /)$.

\begin{abstract}
The international trend of positioning the preschool as a pre-academic learning environment is challenging for preschool teachers, as it necessitates a balance between emotionally supportive interaction and goal-oriented learning instruction. However, previous research suggests that the complexities of such interactions need to be further studied. This article contributes by presenting a very detailed exploration of how social adaptation is pursued in a goal-oriented documentation activity. The study used a micro-sociological approach, characterized by the careful analysis of verbal and nonverbal interactions. Two research questions were raised: (1) How is social adaptation pursued in verbal and nonverbal interactions in preschool teacher-child relationships during a goal-oriented activity? and (2) How can social adaptation in the preschool context be understood in terms of a "deference-emotion system"? Interactions between a teacher and child in two video-recorded episodes were transcribed and sequentially analyzed thoroughly. The findings suggest that the interactions were regulated through an informal system of social sanctions, in which nonverbal signs of deference played a key role. The interaction was shown to be embedded in an institutional context that advocates goal-oriented instruction, thus highlighting the challenge of preschool teaching in attempting to promote goal-oriented processes while simultaneously maintaining respectful, caring teacher-child relationships.
\end{abstract}

Keywords: teacher-child interactions; preschool; micro-analysis; deference-emotion system; social adaptation

\section{Introduction}

This study focuses on the regulation of interpersonal relationships between teachers and children in a goal-oriented Swedish preschool context. Goal orientation in the Swedish curriculum corresponds with a recent shift from a traditionally Nordic social pedagogy approach to an international tradition that entails more clearly pronounced school preparation [1]. The expanding curriculum goals in content areas thus express the global tendency to ensure that children acquire and develop values and knowledge [2]. Positioning the preschool as a pre-academic learning environment also implies strengthened documentation requirements. However, even though Swedish policy documents emphasize that it is the preschool activities that are to be assessed and documented rather than the children, research shows that documentation focuses predominantly on the individual children's learning, emphasizing school-oriented learning [3]. This focus causes the preschool teachers' goal-oriented perspectives to be given precedence over the children's perceptions, with an emphasis on the children's predetermined performance [3-5].

According to international research and policies, the teacher-child relationship is key in children's continued development and learning [3,6-8]. This knowledge places pressure on the competence of preschool teachers during goal-oriented communication with children, as it necessitates a balance between emotionally supportive interaction and pre-academic learning instructions $[9,10]$. The shift toward goal-oriented processes in 
Nordic preschools creates a risk that interpersonal relationship qualities between preschool teachers and children will be neglected. [11].

Education in general—and goal-oriented teaching activities in particular-requires social integration; in this study, social integration is theoretically understood in terms of what Goffman [12] calls the interaction order. That is, the interaction and social behavior of the participants are seen as being organized in an orderly way based on the participants' relations and common norms, but also on institutional practices of "enabling conventions" [12] (p. 5). The participants tend to follow what they perceive as the appropriate interaction order and make arrangements for maintaining it. The analysis is further based on Scheff's [13,14] micro-sociological framework and, in particular, on his deference-emotion system-an informal system of sanctions that promotes conformity in subtle ways.

Research focusing on relationship quality in goal-oriented interactions and on the significance of such interactions for preschool pedagogical practice is scarce $[6,9,15]$, including research on how teachers accomplish interaction with children who act contrary to expectations. Here, on the basis of assumptions of the interaction order [12], we explore how social integration is accomplished on the micro-level [13] of a goal-oriented preschool activity. This exploration was achieved through a meticulous analysis of teacher-child interactions and involved embedded, implicit, and (to some extent) oblivious educational preschool processes.

In a general sense, this study aims to contribute to the knowledge of interpersonal relationships between children and teachers in goal-oriented preschool contexts. More specifically, the aim has an empirical as well as a theoretical purpose: the first is to thoroughly explore how social adaptation is performed in a preschool teacher-child interaction; the second is to discuss this interaction in terms of the deference-emotion system and consider the plausibility of the concept in the current context. Thus, the research questions are as follows:

(1) How is social adaptation pursued in verbal and nonverbal interactions in preschool teacher-child relationships during a goal-oriented activity?

(2) How can social adaptation in the preschool context be understood in terms of a deference-emotion system?

\section{Literature Review}

The field of research concerning the relationship in teacher-child interactions in goaloriented activities in the preschool context constitutes both quantitative and qualitative studies. Quantitative studies are commonly derived from analyses involving relationship or interaction scales in relation to children's development and learning [6-9]. Such studies present parallel conclusions demonstrating that deliberate teacher-child relationships have a positive effect on children's cognitive, social, and emotional development. For example, Lippard et al. [6] examined teacher-child relationships in relation to children's developmental competencies a year later. Their results showed that teacher-child relationships interrelate in various ways with the children's outcomes. Several studies mention the complexities involved in teachers' struggle to maintain a balance between instructional and supportive roles [7-9]. For example, Howes et al. [9] analyzed the quality of the teacher-perceived teacher-child relationship among 118 children and their teachers. Their study implied that the teachers found it difficult to be emotionally supportive and sensitive while simultaneously instructing children in a pre-academic content. The same conclusion is made in Mortensen and Barnett's [7] review of quantitative studies assessing the quality of teacher-child interactions in early childhood education. The review further shows that studies elucidate the processes between teachers and individual children to a limited extent, leaving a gap in explorations of the nature of teacher-child interactions.

A review of qualitative studies in the literature showed that several works examine quantifiable teacher characteristics and child outcomes without fully capturing the nature of these relationships, e.g., [16-18]. Even though conscious relationships between preschool teachers and children are envisioned as a prerequisite for integrating a routine that in- 
terchangeably consists of care and goal-oriented teaching, how this is managed is less studied. Some studies in the Nordic context have also described the challenge of involving children in mutual interaction while simultaneously directing the communication toward specific goals [19,20]. For example, Johansson et al. [20] explored rights and gender in the teacher-child relationship and generated data by collecting 25 video observations of disputes in preschools. Their findings showed that the children were given the right to express their meaning and were listened to; however, the children's rights were constrained if they clashed with institutional rules, and therefore the interactions also comprised social adaptation. Johansson et al. [20] argue that teachers have ambitions for their relationships with the children, "yet these ambitions involve implicit disciplining processes" (p. 222). Parallel findings are presented in Cekaite and Ekström's [19] study of preschool teachers' responses to children's negative emotional expressions. The study involved 35 children and five preschool teachers, and the empirical data consisted of video observations of daily activities. The findings showed that the teachers used communicative genres that prioritized general moral principles and implemented a non-negotiable norm over children's will, emotions, and individual preferences.

In sum, previous research suggests that the quality of goal-oriented teaching in preschools is challenging and is closely related to the nature of teacher-child interactions, but the complexities of these relationships require further exploration $[7,16]$. This study aims to contribute to the field by specifically analyzing how goal-oriented teacher-child interaction is played out in practice and how social adaptation is pursued in this context. This purpose requires in-depth, detailed analysis of verbal and nonverbal interactions, as well as a theoretical framework that is adequate for such micro-analysis.

\section{Theoretical Framework}

The framework used to analyze interactions between preschool teachers and children is based on Scheff's $[13,14]$ theory of a social bond, which focuses on social interactions and interpersonal relationships and assumes that human beings are fundamentally motivated to build social bonds. An individual's personality, basic behavior, and attitudes are understood to be ongoing relational processes.

The assumption is that human interaction occurs via two parallel activity systems: (1) a communication system, which mainly concerns verbal interaction and cognition, and (2) the deference-emotion system, which focuses on nonverbal interaction and emotions [13]. In the current study, the micro-analysis focuses on the latter system. Scheff [13] states, "The documentation of this system has so far escaped the net of systematic research; it is too subtle to be caught by laboratory experiment or social survey. Since it often functions outside the awareness of interactants, field workers have also missed it" (p. 75). In terms of Scheff's [13] theory, shame and pride are defined as basic emotions; their functions are to direct signals to the social self about the quality of a relationship and to guide it in its quest to build strong social bonds. Research on the social function of emotions has shown that feelings of shame are often associated with hiding behavior, while feelings of pride correspond with openness to others [13,21,22]. The degree of mutual respect and associated feelings of pride and shame create a subtle and effective system of informal, social sanctions [13]. The analysis herein is based on the notion that behavior in line with social norms is usually associated with positive sanctions, respectful responses from others, and feelings of pride, while behavior that violates norms is often accompanied by negative sanctions, a lack of respect, and feelings of shame. In other words, conformity is promoted through a system of reward and punishment; people conform even if there are no formal sanctions, such as explicit rules for what to do and how to do it. A deference-emotion system is an informal, subtle process that is largely imperceptible, interwoven in everyday life, and constantly modified via ongoing interaction. Social sanctions and the degree and type of deference, together with the basic emotions of shame and pride, build a system that makes individuals experience social influences as constraints $[13,14]$. 
This study explores what makes interactors (i.e., those who interact) conform to social norms in a goal-oriented preschool context. On the basis of the tenets of the deference-emotion system, the study highlights nonverbal interaction and the degree of deference/respect between a preschool teacher and a child. Emotional aspects are also noticed, albeit to a lesser extent due to a shortage of space.

Importantly, Scheff's $[13,14]$ theory is not understood as normative (i.e., the implication that conformity is necessarily desirable). It is used as an analytical framework to explore the regulation of social in situ interaction, rather than of how social interaction should be. Thus, it was not assumed, a priori, that a seemingly effective deference-emotion system is humane. The model enables discussions, based on empirical data, about whether conformity at the surface level is associated with adequate social bonds, or, conversely, whether it involves the suppression of individual needs. However, this issue is beyond the scope of this article and is not deliberated further.

\section{Materials and Methods}

The analysis in this study draws on empirical data obtained from a former project carried out during the years 2015-2018, in which the aim was to explore preschool teacherchild interaction in everyday preschool documentation practices [5]. Situations that included some sort of documentation were video recorded. Seven teachers and 35 children aged 3-6 years participated. The initial data comprised $267 \mathrm{~min}$ of video recordings. From this data, 173 min where verbal and nonverbal teacher-child interaction took place were selected for further analyses. The selected data were distributed across nine documentation activities that varied in length from 5 to $34 \mathrm{~min}$. The analysis in the former project was based on how social integration was performed by means of the interaction order [12], showing that the teachers and children made different definitions of the activities. The interaction comprised a common pattern involving (1) that the interactions were largely driven by the teachers' questions, (2) the preschool teachers were task-driven and goal-oriented, (3) the preschool teachers modified the interaction processes on the basis of predetermined purposes, and (4) the children adapted to the teachers' definition of the activities. The findings [5] implied that the teachers were task-oriented but the children were not; that is, the teachers expected a particular result of the activity while the children acted more spontaneously. However, the children gradually adapted their actions to harmonize with the teacher's expectations. For the present study, a typical and recurrent example that clearly shed light on the interactional patterns identified in the previous study was selected for an in-depth re-analysis with a focus on how social adaptation was performed on a micro-level. Since the micro-sociological approach implies a close and detailed analysis of interaction, two short episodes from one of the nine activities that distinctly showed the pattern found in the former project was selected.

The project was approved by the Central Ethical Review Board in Linköping (reg. no. 2016/62-31). The re-use of high-quality, existing empirical data was a deliberate choice and is consistent with current ethical considerations (Swedish Research Council, 2017), as the children and preschool teachers did not need to be exposed to new observations. However, the re-use of existing video data necessitates sound knowledge of when, where, and how the data were generated [23]. In this case, the data were generated in the spring of 2016 by one of the authors [5].

\subsection{Video Observations}

Video data have the advantage of involving extensive additional information besides talk-in-interaction, as they depict features-such as gestures, facial expressions, and body movements-that allow researchers to identify subtle events that may be barely discernible in everyday life [24]. In addition, video data allows "permanent records of the social world to be examined and re-examined in the light of different research questions" [25] (p. 289). The sequence of events can also be observed repeatedly from different angles using different theoretical interpretations, thereby providing the researcher with a wealth 
of information [26]. However, video data only represent parts of activities, as recording video - even at an initial stage-involves selection procedures through which, for example, the position of the camera reflects the interest of the researcher [24].

In her article "Key challenges of using video when investigating social practices in education", Blikstad-Balas [27] argues that researchers should aim to focus on details without losing the broader picture. She identifies two risks the video researcher should avoid: (1) solely focusing on major trends in the data, without acknowledging complex details in social practices, and (2) solely focusing on fragments or segments of data, without relating them to the larger pattern of events. This study aimed to avoid both risks by performing an in-depth analysis of situative, contextualized episodes based on typical patterns in a larger data corpus.

\subsection{Analysis}

The analysis in the present paper mainly builds on the American sociologist Thomas Scheff's theory and methodology. Micro-sociological approaches have been used previously in educational research, e.g., [28-30], but less in preschool settings. Scheff $[13,14]$ states that such approaches can supplement both qualitative and quantitative approaches by providing meticulous explorations of interaction and interpersonal relationships in single episodes. According to Scheff [14], research on relationships often refers to abstract ideas about social behavior. In contrast, his approach implies a search for the least possible abstractness, that we "put the discourse that constitutes a relationship under a microscope" (p. 69). A main point is to explore situative, context-specific meanings of phenomena. Therefore, to do justice to the complexity of interactions, analyses usually need to focus on a few episodes. However, the analysis should preferably, as in the current study, be based on a previous analysis through which typical patterns of interaction have been crystallized. As noted above, the micro-analysis in this study focuses on two episodes that were selected because they are characteristic of interaction patterns found in a previous study [5]; that is, in short, the interaction is task-driven and largely controlled by the teacher, and the children, to a great extent, adapt to the teacher's definition. Additionally, the in-depth analysis should be connected to well-defined theory in order to enable discussions of the study's scientific contribution.

Scheff's [13] method is based on Peirce's [31] concept of abduction, which Scheff defines as "the rapid shuttling back and forth between observation and imagination" [13] (p. 31). The researcher oscillates between descriptions of social behavior and reflections on their relational implications. This is a general approach that could be adopted in studies of social interaction in any institutional setting. With an explicit theoretical and methodological framework, opportunities for other researchers to conduct similar research increase. In the present study, the approach has the following implications: we watched the video over and over again, and gradually refined the transcription of what occurs. The video data were thoroughly transcribed, and the interactions were scrutinized sequence by sequence, which is reported below. Moreover, and mostly in parallel, we reflected on and discussed how the observed interaction can be interpreted from Scheff's theoretical framework, that is, what it implies for the construction of interpersonal relationships. Focus was on interpreting connections between small parts, such as an individual's smile, as well as their greater wholes, e.g., their implications for the (ongoing) social bond. The idea was to obtain an understanding as concrete and nuanced as possible of the participants' experiences of the ongoing interaction. However, Scheff [13] suggests that the researcher should focus on certain aspects of the interaction. The basic unit of the analysis, Scheff [13] states, is an exchange- that is, one person's action and another's response. An exchange includes smaller parts, such as individual words and gestures. Aspects such as paralanguage, facial expressions, eye contact, and body movements should be noted. Optimally, the researcher has sufficient information to "climb up and down" a "part/whole ladder" $[13,14]$ - that is, to move from the smallest details in an interaction to the various greater wholes, such as sentences, the entire dialogue, and the whole relationship (as it 
appears in the complete dataset). Scheff [14] states, "There is a microworld underlying social interaction which $(\ldots)$ connects individuals in shared meanings and feelings, and also connects them to the social structure of their society" (p. 190). However, for pragmatic reasons, researchers usually need to focus on certain aspects of "the ladder". The current study focused on exchanges-including individual words and gestures-between a preschool teacher and a child in two brief episodes, as well as on implications for their interpersonal relationship. Expressions occurring in the social and natural world are inherently ambiguous [13]. Therefore, the meanings embedded in words and gestures were carefully analyzed by the researchers, both individually and jointly, with the aim of providing plausible interpretations. In the section below, the reader can take part of the transcripts, follow our interpretations, and reflect on their plausibility.

Thus, the micro-sociological approach was selected in order to present interpretations that are clearly founded in detailed transcriptions of the interactions in the local context while being theoretically substantiated and plausible [13,14,32].

\section{Findings}

The findings of the two episodes are presented sequentially and organized in a threecolumn transcript [33]. The first column indicates the time of the recording, the second provides a transcript of the participants' conversation, and the third documents their nonverbal actions. This is followed by our analysis. A brief description of the course of events that took place between Tables 1 and 2 (10 $\mathrm{min}$ in total) follows after Table 1.

The goal-oriented episodes involve four children (Elof, Anna, Bill, and Clara), each aged roughly 4 years, and a teacher (Petra; all names are fictitious). In the videos, the five participants are sitting at a table with pens and papers. The teacher and Elof, who sit opposite from each other, are the main actors in the episode. The goal-oriented theme that the teacher plans to document is tree-related, and the children have been instructed to draw a tree. The teacher passes out papers and pens to the children, who begin to draw. When the excerpt begins, Clara is showing the teacher her drawing.

Table 1. The first episode.

\begin{tabular}{|c|c|c|}
\hline Recording Time & $\begin{array}{l}\text { Transcript from the } \\
\text { Participants' } \\
\text { Conversation }\end{array}$ & Actions, Gestures, Facial Expressions, etc., of the Participants \\
\hline $03.39-03.41$ & $\begin{array}{l}\text { Teacher: Oh, look! That's } \\
\text { nice! }\end{array}$ & $\begin{array}{l}\text { The teacher turns to Clara, who is showing the teacher a drawing of a tree. The } \\
\text { teacher looks at Clara and gives her a big smile. Elof looks at Clara's drawing. }\end{array}$ \\
\hline
\end{tabular}

03.42-03.44 Elof: Look, I drew!

Elof calls out loudly, emphasizing the word "I." He holds up his drawing for the teacher to see. Initially, he looks at the teacher, then he looks at his drawing; after that, he focuses on the teacher again. The teacher immediately turns to Elof; her smile wanes, and she blinks a few times.

Elof's exclamation is loud and clear. He places emphasis on "I," and his eyes are wide open as he holds up his drawing, which suggests that he is proud of what he has accomplished. Elof copies what Clara did. He shows his drawing to the teacher, with the expectation that he will receive similar acknowledgement. He is anticipating a positive reward but receives a negative sanction, which is shown by the waning of the teacher's smile.

\subsection{4-03.45 Teacher: Yes, what have you drawn now?}

The teacher sits with her hands joined on the table. She lifts her head slightly and looks at Elof with an expressionless face. Her tone is short.

The difference between the teacher's positive response to Clara and her neutral facial expression and blunt tone when she replies to Elof is tangible. She assumes that Elof did not follow the instructions, and conveys this utterance through a subtle negative sanction. 
Table 1. Cont.

\begin{tabular}{lll}
\hline Recording Time & $\begin{array}{l}\text { Transcript from the } \\
\text { Participants' } \\
\text { Conversation }\end{array}$ & Actions, Gestures, Facial Expressions, etc., of the Participants \\
\hline $03.46-03.48$ & Elof: A Santa! & $\begin{array}{l}\text { Elof speaks loudly, emphasizing the word “Santa!" He holds up his drawing } \\
\text { and points to it with his pen; at the same time, he looks at the drawing, then at } \\
\text { the teacher, with a little smile on his face. }\end{array}$
\end{tabular}

Elof answers the teacher's question, once again trying to receive acknowledgement for his drawing. His emphasis on the word "Santa!" is understood as his way of indicating to the teacher that he has also made something worthy of a reward. Elof's smile is analytically interpreted to depict his ambition to be incorporated within the emerging deference-emotion system [13].

03.48-03.49 Teacher: What's that? The teacher regards Elof and his drawing with a neutral facial expression .

The teacher's response implies that the drawing is not in line with the given task. Her attitude continues to be skeptical and signals to Elof that he should align his behavior with the current norms; in other words, he is violating the deference-emotion system [13].

03.49-03.50 Elof: The Santa!

Elof says “The Santa!" with emphasis. He continues to hold up his drawing and pulls his head slightly backward while looking at the teacher.

In this sequence, Elof begins to grasp that his way of solving the task has not adhered to the norm-that is, the interaction order [12], but he still tries to gain the teacher's respect. His voice is relatively strong, just as before, which can be interpreted to reflect that he is still, at least partly, proud of his work. The way he pulls his head back slightly is interpreted as insecurity and as a need to defend himself against the teacher's subtle criticism.

03.50-03.51 Teacher: A Santa? The teacher emphasizes "Santa," quickly leans forward on the table, pulls her head back and looks at Elof. Up until this point, she has been sitting with her hands clasped, but now she starts to fiddle with the pens in her hands.

The teacher's surprised response, expressed using a questioning tone while placing emphasis on "Santa?", and her quick body movements, distances her from Elof's activity.

03.51-03.52 Elof: Umm.

Elof nods, looks at the teacher and smiles slightly. Then he puts the paper on the table, still smiling.

Elof persists that he has drawn a Santa. The way he utters a vague "umm" instead of a clear "yes" and puts down his paper can be an indication that the teacher's sanctions are now more obvious to him. The smile could be a sign of pride (i.e., that he still believes in his activity) or shame (i.e., that he is defending himself against the teacher's sanction).

03.52-03.52 Teacher: Yes, but...

The teacher tilts her head back slightly, purses her lips, fiddles with the pens, and looks at Bill who is seated to her right. Elof looks down at his drawing.

The teacher's remark directly follows Elof's utterance. The word "but" is the teacher's first verbally negative sanction of Elof's activity, and it is accompanied by nonverbal distancing. In the previous sequences, the teacher subtly tried to convince Elof that he needed to change his way of solving the task. Now, the sanction is more obvious. Elof turns his gaze from the teacher and downward, which could reflect that he perceives himself to be negatively valuated.

03.52-03.54 Anna: A Santa! Anna screams as she utters the word and puts a hand up to her mouth just before saying it. Elof, Bill, and the teacher immediately look at Anna.

In line with the teacher's reaction, but involving even more emphasis, Anna expresses surprise that Elof has not drawn what the teacher told them to draw. The way Anna puts her hand up to her mouth can be interpreted as hiding behavior, suggestive of embarrassment/shame [22]; by imagining herself in Elof's situation, she anticipates further negative sanctions. Elof, Bill, and the teacher acknowledge Anna's “dramatic" response, which also indicates that the established deference-emotion system is being upheld by several actors [13].

03.54-03.56 Teacher: A Santa, but you were supposed to draw a tree!
The teacher changes the position of her body and turns slightly to the right, so that she is now turned side on toward Elof, who looks down at his paper and continues to draw. He purses his lips and raises his eyebrows slightly. Anna and Bill stop what they are doing and turn toward Elof.

The teacher's utterance clearly shows that Elof is transgressing the deference-emotion system [13], in which the children are supposed to follow instructions and heed the teacher's negative sanctions. As a nonverbal expression, the teacher's altered bodily position indicates increased disapproval. That Elof purses his lips and lifts his eyebrows indicates that he is now, more than before, experiencing the negative sanction. Anna and Bill stop their activities and turn their attention toward Elof; they are also affected by the informal system of sanctions. 
Table 1. Cont

\begin{tabular}{ll}
\hline Recording Time & $\begin{array}{l}\text { Transcript from the Actions, Gestures, Facial Expressions, etc., of the Participants } \\
\text { Participants' } \\
\text { Conversation }\end{array}$
\end{tabular}

03.56-04.04

During this phase, the teacher, Anna, and Bill watch Elof with neutral faces. Elof continues to draw, with his gaze on the paper. He says, "Look, the Santa will have a hat" (4.00-4.02) and looks up at the teacher. Shortly after, the following takes place:

04.05-04.07 Teacher: But hey, what is

As soon as the teacher starts talking, Elof looks up at her and raises his happening with the tree? eyebrows. The teacher looks at Elof with her head slightly bent. Her body is still turned and is positioned facing halfway to the right. Anna looks wide-eyed at the teacher while chewing a pen. Bill looks at Elof and his drawing with a neutral facial expression.

The question is rhetorical since the teacher knows that Elof is drawing a Santa. Elof's surprised reaction indicates that he is experiencing a strikingly negative sanction from the teacher. Analytically, this response implies that not only his activity, but also his social status is jeopardized. The tension in the situation is also made palpable by the way in which the other children direct their attention toward the two main actors.

04.07-04.09 Elof: It's not going well. Elof looks up at the teacher, nods his head, lifts the pen from the paper, and then looks down at his drawing again. Both Anna and Bill are watching Elof with neutral facial expressions.

Elof has been drawing a Santa for a while now, and he tells the teacher that the task of drawing a tree is not going well. Anna and Bill continue to watch the situation as it unfolds. The way in which they regard Elof with neutral expressions implies that they are continuing to support the teacher's negative sanction of Elof's activity.

04.09-04.10 Teacher: It isn't going well?

The teacher looks at Elof and shakes her head a bit. Bill is alternately watching Elof and the teacher.

The teacher exacerbates Elof's "self-critical" response by repeating his utterance as a question and shaking her head. In this way, her reaction forms part of a chain of negative sanctions. The way that Bill shifts his focus between the teacher and Elof suggests that he is uncertain as to what will happen next.

04.10-04.11 Elof: Noo.

Elof looks down at his drawing, frowns and continues to draw. Anna and Bill focus on Elof.

Once again, having confirmed that the tree drawing is not going well, Elof continues to draw. Looking down while saying "noo" suggests that he wants to hide from the teacher and from the other children, who are tensely following the unfolding of events.

04.10-04.11 Teacher: Noo (hhh). The teacher looks at Elof and moves her head backward slightly. Anna and Bill continue to watch Elof.

The teacher's statement reinforces the message that "it's not going well," which can be interpreted as yet another negative sanction directed at Elof's activity. The other children continue to watch him.

04.11-04.14 Teacher: It turned out to The teacher, Anna, and Bill continue to look at Elof. be a Santa instead.

This statement confirms that Elof has not conformed to the teacher's sanctions. He clearly declares that he did not want to perform the task that the teacher gave and continues to draw a Santa instead. Subtle signs, such as grimacing and blinking, suggest that he was affected by the teacher's sanction; however, his statement indicates a certain level of decisiveness.

04.14-14.19

During this phase, the children continue to draw and engage in small talk. The children start to color their trees. The teacher looks at Elof and asks if he is coloring his tree; he responds non-affirmatively. The teacher reminds him of what he is supposed to do. Elof says that the painting is for his mother. The teacher writes and sits quietly while looking at Elof and his work. Then she asks him to tell her what he was instructed to paint. 
Table 2. The second episode.

\begin{tabular}{lll}
\hline Recording Time & $\begin{array}{l}\text { Transcript from the } \\
\text { Participants' } \\
\text { Conversation }\end{array}$ & Actions, Gestures, Facial Expressions, etc., of the Participants \\
\hline $14.19-14.20$ & $\begin{array}{ll}\text { Elof: ... With Santa, don't } \\
\text { want to paint anymore. }\end{array}$ & $\begin{array}{l}\text { Elof looks down at his drawing and then up at the teacher, waving his brush } \\
\text { over the drawing. "... Santa" is expressed quietly, with short breaks between } \\
\text { the words. He stops waving his brush and looks at the teacher when he says } \\
\text { "paint anymore". }\end{array}$
\end{tabular}

Elof repeats "Santa," but quietly this time, which appears to be his last attempt to be rewarded for his drawing. The short breaks and his words "don't want to paint anymore," together with the fact that he directs his gaze at the teacher and stops waving his brush, suggest that he is dissatisfied and has given up.

14.20-14.21 Teacher: Oh no, have you The teacher holds the can of paint and hands it to another child who asked for made a tree? it. She holds a pen in the other hand, while looking at Elof, nodding her head. Her tone is sharp.

The teacher here asks a question that implies that Elof has done something other than what he claimed. The direct question and tone of voice can be interpreted as an attempt to control Elof's behavior more rigidly.
$14.21-14.22$
Elof: Yes
Elof moves around on the chair, holding the brush in his hand. At first, he looks down sideways, then up at the teacher. His response is quick.

Elof's prompt response to the teacher's question implies an obvious change of strategy.

$\begin{array}{ll}\text { 14.22-14.23 Elof: Here. } & \text { Elof waves the brush over his drawing, looks down at it and then at the } \\ \text { teacher. The teacher tilts her head slightly. }\end{array}$

The way Elof waves his brush over his drawing suggests that he is unsure as to where the tree is, which is understandable, since it is a Santa.
$14.25-14.26$
Teacher: Where is...?
The teacher stands up and walks toward Elof. He waves the brush over the drawing.

The teacher's movement can be interpreted as a controlling approach to determine whether Elof has understood the previous corrections of his behavior. She also asks for clarification with the words "Where is ... ?"

$\begin{array}{ll}\text { 14.26-14.28 Elof: Many trees. } & \text { Elof waves his brush over the drawing, looks at the teacher and then down at } \\ \text { his drawing. He says "many" with a strong voice while looking at the teacher. }\end{array}$

The use of "many trees," stated in a strong voice while looking at the teacher, can be understood as Elof's way of ensuring that the task will be positively validated. Analytically, this suggests that he has realized how the deference-emotion system [13] works and how to avoid negative sanctions.

\section{Discussion}

Drawing on the tenets of the deference-emotion system [13], this study's meticulous analysis of preschool teacher-child interactions explored the pursuit of social adaptation during a goal-oriented activity in an institutional context.

\subsection{The Pursuit of Social Adaptation in the Child-Preschool Teacher Interaction}

Previous research indicates that simultaneously balancing supportive instruction with goal-oriented instruction is challenging and has an obvious impact on the child-teacher interaction; nevertheless, the nature of such interaction is seldom studied e.g., $[7,9,16]$. Although several studies reveal the importance of attentive interactions that intertwine care with goal-oriented teaching e.g., [7,16-18], such interactions are-as seen here-extremely multilayered, making a micro-level analysis necessary to elucidate the teachers' and children's interactional possibilities. From the analyzed episodes in this study, it is clear that Elof's drawing of a Santa diverged from the goal-oriented activity of drawing trees, resulting in the social adaptation being managed through various subtle sanctions from the teacher to make him align with the overall interaction order [12]. The episodes revealed micro-political conflict between the teacher's endeavors to make Elof conform with the goal-oriented activity and his desire to do something else. The analysis showed that social adaptation was pursued by the teacher's informal, subtle, nonverbal influence through the following nonverbal expressions: (1) a neutral facial expression, (2) a tense tone, 
(3) a reticent body position, (4) a hard-set mouth, and (5) denial through head movements (e.g., shaking her head to reinforce Elof's statement, "it isn't going well"). However, as shown here, subtle signals of the need for adjustment can be difficult for children to grasp, which aligns with the work of Johansson et al. [20]. Elof's adaptation was displayed in how he increasingly conformed to the preschool teacher's verbal and nonverbal expressions and subtle social norms. This shift in his behavior was elucidated by the difference in his expression at the start of the episodes (i.e., speaking with a strong voice, a focused gaze, and pride, and showing his drawing) and his expression toward the end of the episodes (i.e., speaking with a quiet voice and lowered gaze, and remarking that he did not want to draw a tree). The subtle weight of deference as a vital component of the system was evident in the latter episode, when Elof confirmed that he did not wish to draw anymore.

Consequently, following Karlsudd [3], the present study shows that, even though it is the preschool activities that should be documented and assessed, the individual children's achievements of the objectives are foregrounded. Furthermore, although preschool teachers' desire to ensure conformity [13] is based on respect for the children, it includes a disciplinary process that may undermine democratic values during interactions. However, video observation enables extremely close and accurate descriptions, and it is important to acknowledge that the interactional order [12] in ongoing interactions is rarely perceived by the participants [32]. Accordingly, the regulation of children by the teacher at the micro-level is not primarily a conscious choice. It should rather be regarded as only possible to perceive by means of in-depth analysis that make visible what is otherwise hidden and should thereby be understood as part of a goal-oriented framework within the institutional context.

\subsection{An Understanding of Social Adaptation in Preschools According to the Deference-Emotion System}

By applying Scheff's $[13,14]$ framework, the analysis showed that social adaptation in the episodes was performed through subtle social sanctions and interactive signals of deference/respect. According to the micro-study, the deference-emotion system is a plausible framework for understanding why the interactors in preschool conform, even if there are no formal sanctions, and even if they do not want to. This approach makes it possible to analyze events that are difficult to discern in pedagogical practice; it also demonstrates the informal and meshed nature of conformity. In this regard, social adaptation occurs through verbal behavior and cognitive processes, as well as through nonverbal behavior and emotional processes. The current study suggests that nonverbal behavior plays a particularly important role in social adjustment in the preschool context.

In the episodes, the deference-emotion system was initially activated by rewarding instructional behavior with positive sanctions and by discouraging non-conformist behavior with negative sanctions. The analysis suggested that Elof persisted with his own activity regardless of the teachers' and other children's actions, but gradually adapted to the interaction order. His quick and affirmative response that he had drawn a tree, at 14.21 , is probably the clearest indication of the power of the deference-emotion system. According to the analysis, the child conformed by seeking to maintain social bonds with the teacher and be positively valued by the teacher.

Thus, the strength of the deference-emotion system gradually became clear, showing how the teacher's sanctions influenced the child's behavior and supported the informal norms. Step by step, the teacher demonstrated what the children should do and how they should act, albeit without issuing an explicit interaction order. The analysis suggested that teachers utilize three alternative approaches to accomplish social adaptation: (1) requiring obedience by controlling the children's behavior (which occurs in part in the present episodes); (2) relying on the self-control of the children, which ensures adherence to the prevalent norms (which also occurs in part in these episodes); and (3) assisting the children to adjust their behavior through interactions (which seems to be the main approach followed by the teacher in these episodes) [21]. In Western discourse on preschool education, the third approach is undoubtedly the most dominant. This prevalence raises 
questions regarding how teachers encourage children to act and interact in accordance with prevalent norms and how predefined goals are achieved without resorting to constraints or sanctions, which children experience as intimidating.

Of course, social adaptation does not necessarily mean good education. Beneath the surface of a seemingly well-functioning, goal-effective interaction order, other goals and values may be neglected. Therefore, it would indeed be risky to use the theoretical model-and the results of this study - as a means to achieve conformity. On the other hand, we suggest that the outlined framework could function as a tool for reflection on how to promote education that is both respectful and productive.

\subsection{Interpersonal Relationships between Teachers and Children in Goal-Oriented Contexts}

As indicated previously, Swedish preschools are part of a goal-oriented education system, which necessitates documentation [2]. Preschool teachers are subjected to changes in their professional assignments, with consequences for instructional activities and the teaching practice at large. Although the children do not have specified goals to accomplish, activities implemented by the preschool teachers are expected to lead to a result that can be documented. In line with the work of Karlsudd [3], the documentation practice in preschool is revealed in the current study to be strongly individual-centered. Karlsudd [3] uses the terms "narrow" and "wide" to describe different conceptions of normality in preschools. According to the wide perspective, the environment/activity should be adapted to the child; according to the narrow perspective, the child should be adapted to the environment/activity through corrective and compensatory measures. Compared with the discussion above regarding teachers' alternative approaches to accomplishing social adaptation, our study has shown the complexities and the nature of such interaction, indicating that there is a thin line between deliberate gentle guidance and subtle embedded sanctions.

An individual-centered society, which strongly stresses cognitive aspects at the expense of socio-emotional aspects [34], corresponds well with a narrow preschool perspective. In a goal-oriented context with a predetermined pre-academic direction, there is a risk of overlooking socio-emotional aspects.

Children's end products provide a concrete object to be documented and a certain guarantee that preschool teachers have fulfilled their assignment. In the analyzed episodes, the preschool teacher's subtle regulations, which finally resulted in the intended end product, were understood to be institutionally functional. The interaction order [12] inherent in our analysis is an example of a regular interaction pattern in the institutional context; in terms of goal-oriented preschool activities, it did not reflect an individual teacher's way of communicating. Teaching and the instruction of predefined goals always involve a certain process of influence [35]. However, when studying goal-oriented activities in preschool contexts, it is important to elucidate both prevailing institutional conditions and preschool teacher-child interaction on a micro-level. It is also necessary to acknowledge the deference-emotion system, how it functions to adapt children's and teachers' behavior to the advocated interaction order, and what this adaptation may imply for educational purposes in a wider sense.

\subsection{Limitations, Suggestions on Further Research, and Implication for Practice}

The study has some important limitations, which should be kept in mind when interpreting the findings. First, although the micro-analysis is based on interaction patterns detected in a previous study, we cannot claim that the result-that is, that social adaptation in the episodes is pursued by means of an informal system of sanctions-is typical for goal-oriented preschool practices in general. In other words, from the findings, it is not possible to draw overall conclusions about preschool education. Second, although the adoption of the deference-emotion system in this study includes reflections on emotions, it mainly focuses on the degree of deference. An expanded analysis of the episodes based on emotions was not possible due to a shortage of space. This limits the understanding of the 
interactors' perspective and of the theoretical concept. Third, although the micro-analysis, in accordance with Scheff's $[13,14]$ approach, includes the perspectives of the interactors, the interpretations are based on descriptions of social interaction. That is, the interactors' own versions of what occurred in the brief episodes are not included. Consequently, further micro-sociological research on social adaptation in preschool could (1) focus on how common the identified interactional patterns are; (2) perform more in-depth studies of the emotional aspects of interaction; and (3) include preschool teachers' and children's (own) perceptions of interaction, for example by using stimulated recall interviews.

The ambition with the analyzed episode is not to state how goal-oriented activity should or should not be conducted. Rather, we have analytically elucidated the complexity of teachers' dual assignment in order to incorporate both goal-oriented activities and be emotionally supportive. The study also implies that educators should acknowledge that goal-oriented approaches might overshadow interactional and relational qualities in the process. Finally, the micro-analysis suggests that the deference-emotion system is a valuable concept for understanding goal-oriented activities; for example, it clearly elucidates that this system, in practice, sometimes can have a repressive function, and limit the agency for both preschool teachers and children.

\subsection{Conclusions}

Previous research on preschool education has revealed that adequate balance between supportive interaction and pre-academic instruction is a complex task. Research also shows that, in goal-oriented education, teachers' perspectives tend to be given precedence over the children's perceptions. Moreover, research suggests that social adaptation in preschool involve implicit disciplining processes. The present study contributes by showing in great detail how social adaptation is performed in practice, and how this process could be conceptualized.

To gain in-depth knowledge of an educational phenomenon, such as social adaptation, we need approaches designed to explore social interaction in its full complexity. The current study shows that Scheff's micro-sociological approach is relevant for exploring social adaptation in preschool. Findings were discussed above, structured by the research questions, and can now be compiled as follows: First, the study shows that social adaptation in the goal-oriented preschool context is pursued in interactions that are highly vulnerable. The preschool teacher and, primarily, the children seem extremely sensitive to what occurs in the "here and now", to signals of deference, and to what these signals imply for their interpersonal status. The study also contributes by highlighting the importance of nonverbal interaction for social adaptation, and, more generally, for the socialization of children in preschool. Second, conformity by the participants to the social norms revealed that a system of informal respect and social sanctions was established. The teacher and the children seem to conform by seeking to maintain social bonds and be positively valued by others. The study thus demonstrated the power of "the deference-emotion system", that is, it suggests that this system is a plausible and useful framework for analyzing and understanding social adaptation in preschool.

Author Contributions: K.N. was active in the planning of the study and in the gathering of empirical material, i.e., the video documentation for the study. K.N. was responsible for processing the empirical material, for analyzing the data and also for selecting data for the study. K.N. is the person responsible for developing the text at all stages. J.A. and A.L.-A. played important parts in the design of the study. They contributed to the theoretical, analytical and methodological parts and critically read and commented drafts at all stages. All authors have read and agreed to the published version of the manuscript.

Funding: This research received no external findings.

Institutional Review Board Statement: The study was conducted according to the guidelines of the Declaration of Helsinki, and approved by the Central Ethics Review Board in Linköping (no. 2016/62-31). 
Informed Consent Statement: Written informed consent has been obtained from the participating teachers and the parents from the participating children to publish this paper.

Data Availability Statement: The videos are stored in accordance with current safety regulations at Kristianstad University.

Conflicts of Interest: The authors declare no conflict of interest.

\section{References}

1. Persson, S. Pedagogiska Relationer i Förskolan. Tidig Intervention Förskola. [Pedagogical Relationships in Preschool. Early Intervention Preschool]; The Swedish Research Council's Reports Research and School in Collaboration-Mapping of Research Results with Relevance for Practical work in the School System; The Swedish Research and the Swedish Institute for Educational Research Council: Stockholm, Sweden, 2015; Available online: https://www.vr.se/download/18.2412c5311624176023d25ac7/15554231059 13/Foerskola-tidig-intervention_VR_2015.pdf (accessed on 14 May 2020).

2. Swedish National Agency for Education. Läroplan för Förskolan: Lpfö 18 (Curriculum for Preschool); Skolverket: Stockholm, Sweden, 2018; Available online: https:/ / www.skolverket.se/download/18.6bfaca41169863e6a65d5aa/1553968116077/pdf4001 (accessed on 29 October 2021).

3. Karlsudd, P. When differences are made into likenesses: The normative documentation and assessment culture of the preschool. Int. J. Incl. Educ. 2021, 1-17. [CrossRef]

4. Emilson, A.; Pramling Samuelsson, I. Documentation and communication in Swedish preschools. Early Years 2014, 34, 175-187. [CrossRef]

5. Nilfyr, K. Dokumentationssyndromet-En Interaktionistisk och Socialkritisk Studie av Förskolans Dokumentations-Och Bedömningspraktik. [The Documentation Syndrome-An Interactionist and Socially Critical Study of the Preschool's Documentation and Assessment Practice]; Licentiatuppsats, Linnaeus University: Kalmar, Sweden, 2018.

6. Lippard, C.; La Paro, K.; Rouse, H.; Crosby, D. A closer look at teacher-child relationships and classroom emotional context in preschool. Child Youth Care Forum 2017, 47, 1-21. [CrossRef]

7. Mortensen, J.A.; Barnett, M.A. Teacher-child interactions in infant/toddler childcare and socioemotional development. Early Educ. Dev. 2015, 26, 209-229. [CrossRef]

8. Sabol, T.; Pianta, R.C. Recent trends in research on teacher-child relationships. Attach. Hum. Dev. 2012, 14, 213-231. [CrossRef] [PubMed]

9. Howes, C.; Sidle Fuligni, A.; Soliday Hong, S.; Huang, Y.D.; Lara-Cinisomo, S. The preschool instructional context and childteacher relationships. Early Educ. Dev. 2013, 24, 273-291. [CrossRef]

10. Sheridan, S.; Pramling Samuelsson, I. Preschool: A source for young children's learning and well-being. Int. J. Early Years Educ. 2013, 21, 207-222. [CrossRef]

11. Aspelin, J.; Persson, S. Om Relationell Pedagogik. [On Relational Pedagogy]; Gleerups: Malmo, Sweden, 2011.

12. Goffman, E. The interaction order: American Sociological Association, 1982 Presidential Address. Am. Sociol. Rev. 1983, 48, 1-17. [CrossRef]

13. Scheff, T. Microsociology, Discourse, Emotions and Social Structure; The University of Chicago Press: Chicago, IL, USA, 1990.

14. Scheff, T. Emotions, the Social Bond and Human Reality. Part/Whole Analysis; Cambridge University Press: Cambridge, UK, 1997.

15. Dalgren, S. Att Göra Pedagogisk Praktik Tillsammans: Socialt Samspel i Förskolans Vardag. [Doing Pedagogical Practice Together: Social Interaction in Preschool Everyday Life]. Ph.D. Thesis, Linköping University, Linköping, Sweden, 2017.

16. Hall-Kenyon, K.M.; Rosborough, A.A. Exploring pedagogical relationships in the context of free play. Early Years 2017, 37, 326-337. [CrossRef]

17. Lim, C.; Lim, S.M. Learning and language: Educarer-child interactions in Singapore infant-care settings. Early Child Dev. Care 2013, 183, 1468-1485. [CrossRef]

18. McNally, S.; Slutsky, R. Teacher-child relationships make all the difference: Constructing quality interactions in early childhood settings. Early Child Dev. Care 2018, 188, 508-523. [CrossRef]

19. Cekaite, A.; Ekström, A. Emotion socialization in teacher-child interaction: Teachers' responses to children's negative emotions. Front. Psychol. 2019, 10, 1-19. [CrossRef] [PubMed]

20. Johansson, E.; Emilson, A.; Röthle, M.; Puroila, A.M.; Broström, S.; Einarsdóttir, J. Individual and collective rights expressed in educator and child interactions in Nordic preschools. Int. J. Early Child. 2016, 48, 209-224. [CrossRef]

21. Aspelin, J. Sociala Relationer och Pedagogiskt Ansvar. [Social Relationships and Educational Responsibility]; Gleerups: Malmo, Sweden, 2010.

22. Retzinger, S.M. Violent Emotions: Shame and Rage in Marital Quarrels; Sage Publications: London, UK, 1991.

23. Derry, S.J.; Pea, R.D.; Barron, B.; Engle, R.A.; Erickson, F.; Goldman, R.; Hall, R.; Koschmann, T.; Lemke, J.; Gamoran Sherin, M.; et al. Conducting video research in the learning sciences: Guidance on selection, analysis, technology, and ethics. J. Learn. Sci. 2010, 19, 3-53. [CrossRef]

24. Heath, C.; Hindmarsh, J.; Luff, P. Video in Qualitative Research. Analysing Social Interaction in Everyday Life; Sage Publications: London, UK, 2010.

25. Goodwin, C.; Heritage, J. Conversation analysis. Annu. Rev. Anthropol. 1990, 19, 283-307. [CrossRef] 
26. Aspelin, J. We can recite it in chorus now: An interactionist approach to the teacher-student relationship and teachers' relational competence. Classr. Discourse 2017, 8, 55-70. [CrossRef]

27. Blikstad-Balas, M. Key challenges of using video when investigating social practices in education: Contextualization, magnification, and representation. Int. J. Res. Method Educ. 2017, 40, 511-523. [CrossRef]

28. Aspelin, J. Beneath the Surface of Classroom Interaction: Reflections on the Microworld of Education. Soc. Psychol. Educ. 2006, 9 , 227-244. [CrossRef]

29. Beaulieu, R. A critical discourse analysis of teacher-student relationships in a third-grade literacy lesson: Dynamics of microaggression. Cogent Educ. 2016, 3, 1-20. [CrossRef]

30. Ljungblad, A.-L. Takt och Hållning. En Relationell Studie om det Oberäkneliga i Matematikundervisningen [Tact and Stance]. Doctoral Thesis, Gothenburg University, Gothenburg, Sweden, 2016.

31. Peirce, C.S. Abduction and Induction. In Philosophical Writings of Peirce; Buchler, J., Ed.; Dover Publications: New York, NY, USA, 1955; pp. 150-156.

32. Koschmann, T.; Stahl, G.; Zemel, A. The video analyst's manifesto (or the implications of Garfinkel's policies for studying instructional practice in design-based research. In Video Research in the Learning Sciences; Goldman, R., Pea, R., Barron, B., Derry, S.J., Eds.; Routledge: Milton Park, UK, 2007; pp. 133-143.

33. Jordan, B.; Henderson, A. Interaction analysis: Foundations and practice. J. Learn. Sci. 1995, 4, 39-103. [CrossRef]

34. Scheff, T. A social/emotional theory of "mental illness". Int. J. Soc. Psychiatry 2013, 59, 87-92. [CrossRef] [PubMed]

35. Mercer, N. Culture, context and the construction of knowledge in the classroom. In Context and Cognition: Ways of Learning and Knowing; Light, P., Butterworth, G., Eds.; Lawrence Erlbaum Associates: Mahwah, NJ, USA, 1992; pp. $28-46$. 